\title{
Small Oil Burner Concepts Based on Low Pressure Air Atomization
}

\author{
T. Butcher, Y. Celebi, G. Wei, and B. Kamath* \\ Brookhaven National Laboratory \\ ${ }^{*}$ Heat Wise, Inc.
}

reprint of a paper presented at:

Second European conference on Small Burner and Heating Technology

University of Stuttgart

March 16-17, 2000

Energy Sciences \& Technology Department

Energy Resources Division

Brookhaven National Laboratory

Brookhaven Science Associates

Upton, Long Island, New York 11973

Under Contract No. DE-AC02-98CH10886 with the

United States Department of Energy 


\title{
Small Oil Burner Concepts \\ Based on Low Pressure Air Atomization
}

T. Butcher, Y. Celebi, G. Wei, and B. Kamath*

Brookhaven National Laboratory

Energy Sciences and Technology Department

Energy Resources Division

Building 526 Upton, N.Y. 11973

* Heat Wise, Inc., Ridge N.Y.

\begin{abstract}
The development of several novel oil burner applications based on low pressure air atomization is described. The atomizer used is a prefilming, airblast nozzle of the type commonly used in gas turbine combustion. The air pressure used can be as low as 1300 $\mathrm{Pa}$ and such pressure can be easily achieved with a fan. Advantages over conventional, pressure-atomized nozzles include ability to operate at low input rates without very small passages and much lower fuel pressure requirements. The development of three specific applications is presented. The first two are domestic heating burners covering a capacity range 10 to $26 \mathrm{~kW}$. The third application presented involves the use of this burner in an oil-fired thermophotovoltaic power generator system. Here the design firing rate is 2.9 $\mathrm{kW}$ and the system produces 500 watts of electric power.
\end{abstract}

\section{Introduction}

At very low firing rates the small passage sizes in pressure swirl nozzles lead to poor reliability and this factor has practically constrained these burners to firing rates over 14 $\mathrm{kW}$. Air atomization can be used very effectively at low firing rates to overcome this concern. However, many air atomizer designs require pressures which can be achieved only with a compressor, greatly complicating the burner package and increasing cost. The work described in this paper has been aimed at the practical adaptation of low pressure air atomization to low input oil burners. The objective of this work is the development of burners which can achieve the benefits of air atomization with air pressures practically achievable with a simple burner fan.

Three specific applications of this approach are described in the following sections and each of these applications is in a quite different state of technical development. In the first a domestic heating burner is described which uses components as conventional as possible. The burner head in this case has been developed to enable operation over a wide firing rate range. This burner is, at present, fully certified in the U.S. and in extended field trials. The second application is also for domestic heating applications but uses non-traditional components. The head design is simpler but has been designed for a smaller range of firing rates.

The third application developed does not involve domestic heating, but rather an oil-fired thermophotovoltaic power generator system. This system is being developed as a 
Two additional reports are available which provide documentation of some of the development steps for the domestic heating burners. [1,2].

\section{Description of the Atomizer}

The nozzle can be characterized as a low pressure, prefilming, airblast atomizer typical of those used in gas turbine combustors [3]. A cross section illustration is provided in Figure 1.

Air entering the back of the nozzle is internally divided into two parts. Most of the air passes through the outer swirler and spins out through the main exit orifice. A smaller amount passes radially inward through four small, offset holes ("A" in

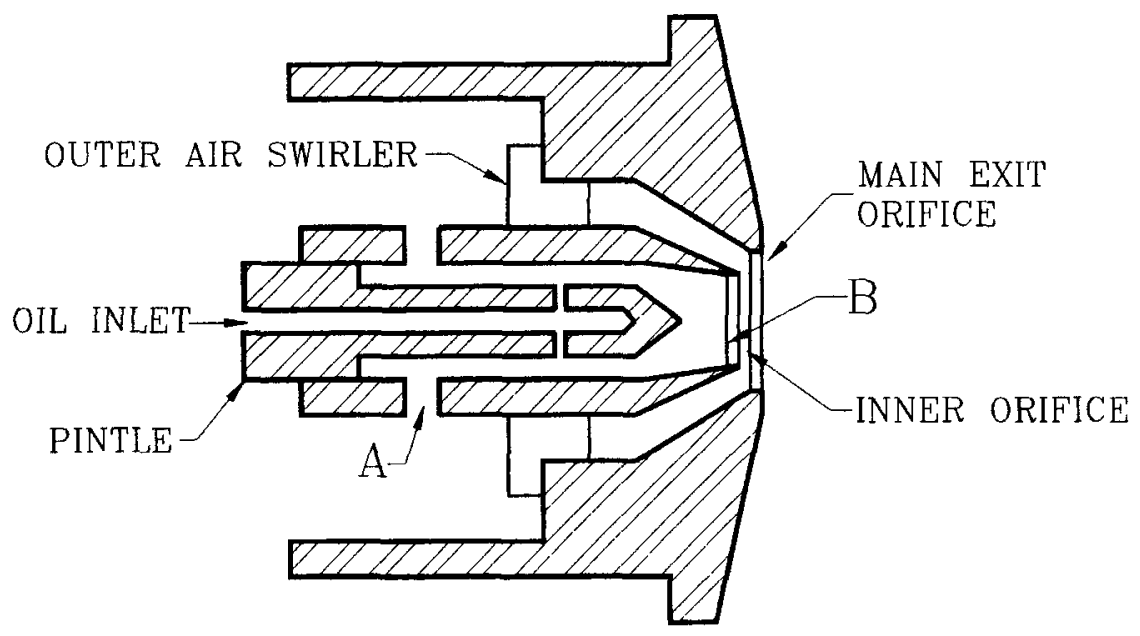

Figure 1), providing counter swirling air around the pintle. Fuel enters the back of the nozzle and is injected, through small, radial holes onto the inner surface of the "swirler". The swirling air distributes and swirls the oil, prefilming it as it leaves the inner orifice ("B"). The size and number of the oil injection holes depends upon the firing rate, but typically 2 or 3 holes are used with diameters 200 to 400 microns. The design criteria here is the form of the exit jet. If the velocity is too low the fuel may exit as a poorly formed jet or even drip, resulting in an uneven film on the inner surface of the swirler. Fuel pressure at the nozzle is typically 0.1 bar.

The swirl downstream of the nozzle is primarily dominated by the axial swirl vanes inside of the nozzle. The swirl level can be characterized as "weak" and a recirculation zone on the axis of the flow is not produced. The important implication of this is that the flame must be stabilized with an "external" rather than an "internal" recirculation pattern.

The general atomization performance of airblast atomizers have been well studied [3]. Droplet size is strongly influenced by atomizer air/fuel ratio and air velocity. Increasing the air pressure as well as the fraction of the total combustion air which passes through the atomizer will both reduce drop size. In this work the performance of atomizers is measured using a laser diffraction sizer. Generally, the atomizer used here can produce similar or better performance than conventional, pressure swirl nozzles with air pressure over $1300 \mathrm{~Pa}$. 
The pattern or "spray angle" produced by the nozzle can be influenced by the angle of the axial swirl vanes on the nozzle swirler. A typical pattern, produced with $30^{\circ}$ vanes is illustrated in Figure 2.

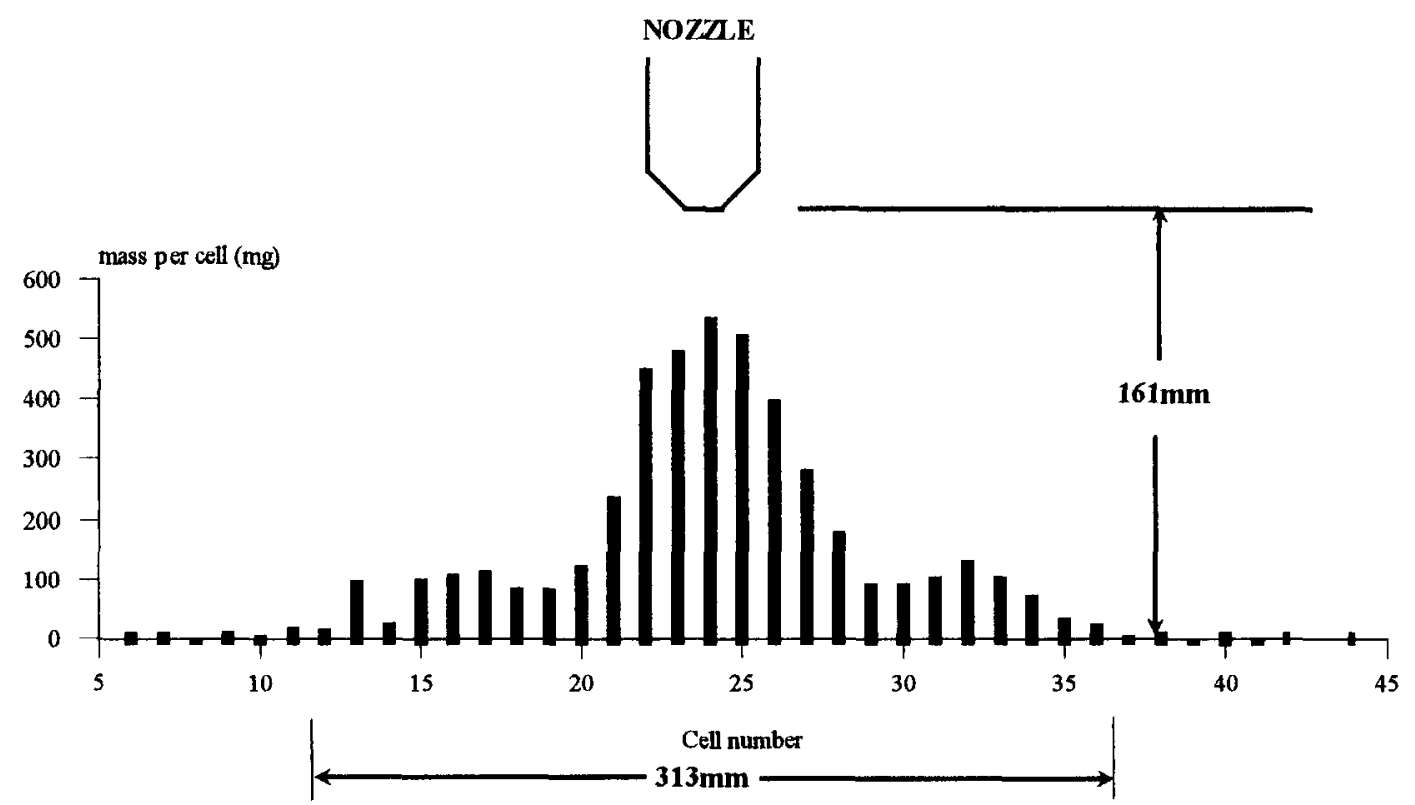

Figure 2. Illustration of typical spray pattern

\section{Application 1. Domestic Heating}

The first head arrangement developed is illustrated in Figure 3 and this follows a similar arrangement used in traditional, retention head burners. All of the air from the burner's fan is delivered into the air tube plenum behind the burner head. At the head the air is divided into three different parts: primary air - which passes through the nozzle, atomizing the oil; secondary air - which passes through small slots on the face of the burner head, primarily serving to keep the face clear from coke deposits; and tertiary air which enters the flame zone through an adjustable annular opening around the outer edges of the head. As in many traditional burners the head can be moved in and out to provide a range of excess air and firing rate adjustment. In this design the full air pressure from the fan, in the range of $1300 \mathrm{~Pa}$, is available at the back end of the head. Tertiary air velocity is high and this has considerable influence on the flow patterns within the flame zone. In addition, the tertiary air annular opening is small, on the order of $1.3 \mathrm{~mm}$ and some care must be taken in design to assure a uniform gap around the circumference.

The fan used in this application is a conventional oil burner fan, driven with a $3450 \mathrm{rpm}$ AC motor on a single shaft with a conventional gear-type fuel pump. A flow metering orifice between the pump and the nozzle is used to control firing rate and keep the fuel pressure at the nozzle at the 0.1 bar level. In field tests the fuel pump pressure has been evaluated at both low $(0.4 \mathrm{bar})$ and high $(7 \mathrm{bar})$ levels. The issue of fuel pressure to be 
employed is not really combustion related but rather related to reliability of regulation and the performance under conditions of partial fuel filter and line blockage. The burner uses a conventional "cad cell" operating control and interrupted ignition.

This arrangement has been taken to commercial status as the Pioneer burner. It is fully approved for commercial use in the U.S. over the firing rate range of 12 . to $25 \mathrm{~kW}$. Field trials are in progress.

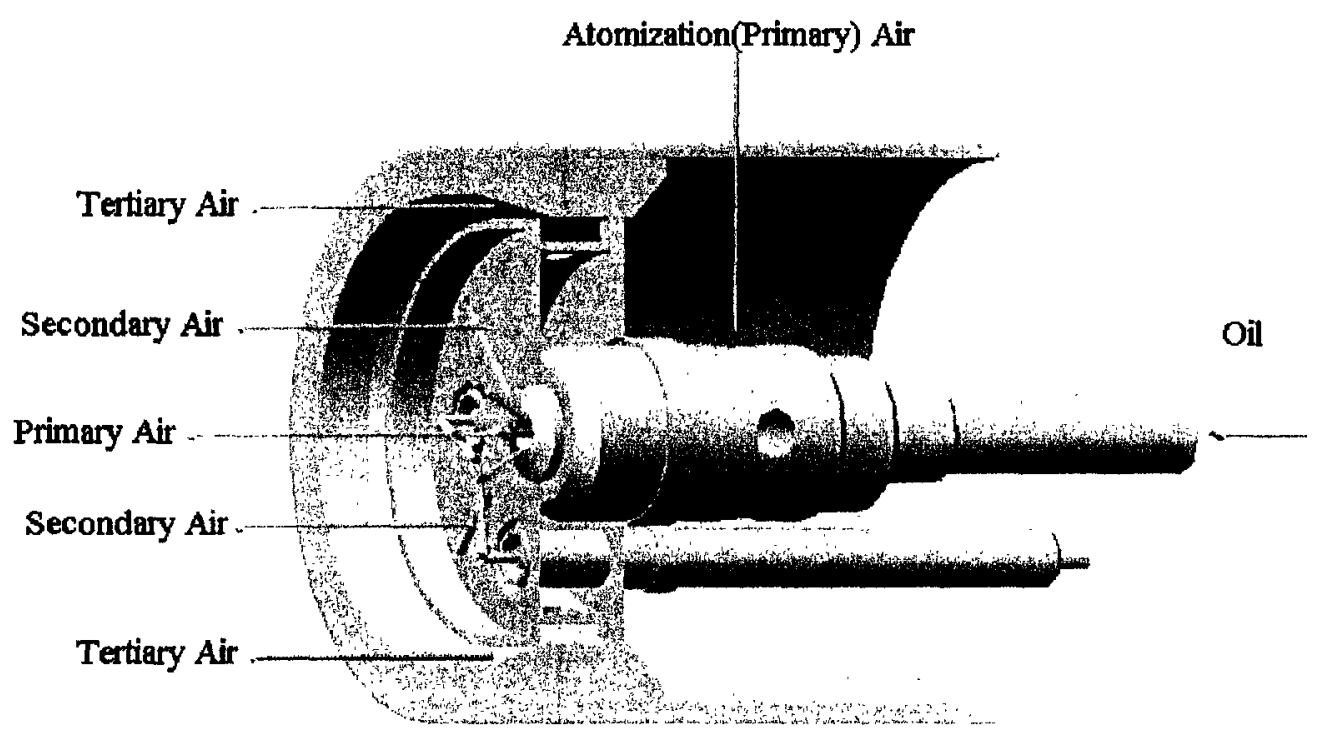

Figure 3. Burner head arrangement \#1

\section{Application 2. Domestic Heating}

A second, considerably different, burner head is currently under active development with the objectives of a simpler head relative to the Pioneer burner and a higher fraction of total combustion air flow through the atomizing nozzle. Figure 4 shows the general arrangement of the air tube, burner head, and flame tube.

All of the air from the fan in this case is delivered into a central feed tube with the nozzle at the far end. Radial holes around the air tube allow a small fraction $(\sim 30 \%)$ of the total flow to pass out of this central air tube into the surrounding annular space. This secondary air then flows axially down, entering the flame zone as low velocity $(.5 \mathrm{~m} / \mathrm{s})$ secondary air. The flow pattern in the flame zone is essentially a strong central, swirling jet with a torroidal recirculation pattern. The flame tube, choke ring, and recirculation slots shown serve to provide flame stability and a controlled amount of recirculation of cooler gas from outside of the flame tube back into the flame zone. The emission levels of $\mathrm{NO}_{\mathrm{X}}$ from the burner can be adjusted by allowing greater amounts of recirculation. However, for the U.S. markets $\mathrm{NO}_{\mathrm{X}}$ emissions are not an important technology driver and the paramount design parameter has been compatibility with a common, yellow flame burner operating control. 
With the burner configured as shown there is obviously no provision for flow control. This burner is intended as a fixed firing rate unit without excess air adjustment ability except through fuel pressure adjustment. All current work is focused on an input rate of $13.5 \mathrm{~kW}$, although smaller and larger heads have been built.

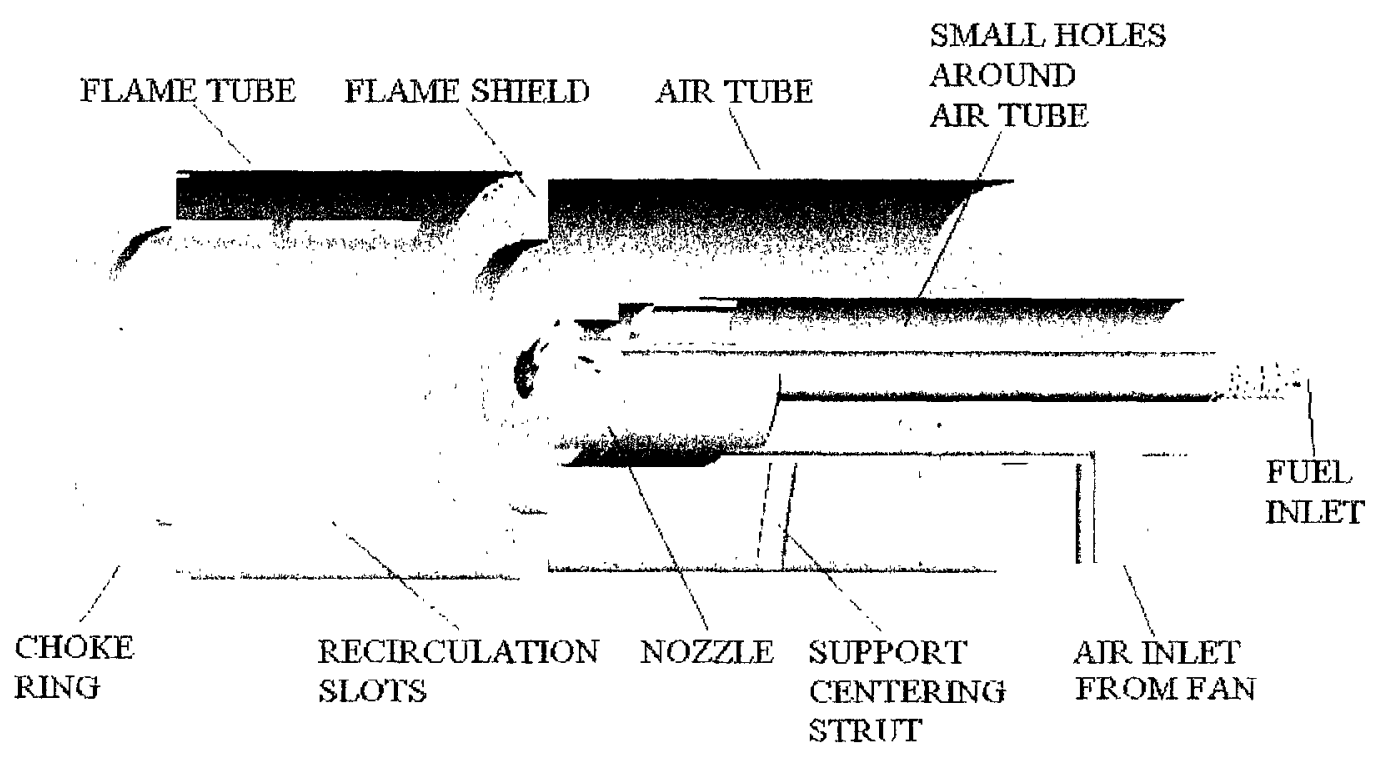

Figure 4. Burner head arrangement \#2

The choke ring at the end of the flame tube can be eliminated if the flame tube were made longer and some development effort has been placed in this direction. However, the burner must be compatible with typical U.S. cast iron boilers which can have a very short length available in the combustion chamber.

The current prototype burner system based on this head arrangement is based on nonconventional components. The fan is a brushless DC blower / fan set with a maximum static pressure of $2000 \mathrm{~Pa}$. Fuel is delivered using a discrete solenoid pump with integral pressure regulator set at 2.1 bar. A conventional operating control is used with interrupted ignition. Configured in this way the system electric power draw is 65 watts.

The prototype of this burner started field trials during the 1999/2000 heating season.

\section{Application 3. Thermophotovoltaic Generator}

The final application discussed for this combustion technology in the earliest stages of development. It is to be used in a portable 500 watt electric power generation system based on thermophotovoltaics (TPV).

TPV is an approach to convert thermal energy from a hot body released in the form of infrared radiation to electric energy. It is possible to produce such a hot body by the combustion of liquid fuel inside a suitable emitter such as silicon carbide. When the radiation from the emitter is directed to a photovoltaic cell, that part of the infrared 
radiation available from blackbody emission that matches the bandgap of the PV cell is converted into electricity. For the TPV system to achieve reasonable conversion efficiency, it is necessary to control the spectrum, incident on the photovoltaic cells. For example, photons with energies lower than the band gap of the PV cell can not generate electricity but become waste heat that has to be rejected from the cells. Two basic approaches have been taken to control the spectrum. The first involves selective emitters. A selective radiator, made using oxides of rare earth elements such as ytterbium has a high emissivity in a relatively narrow band of wavelengths. The region of high emissivity from the radiators is matched with the bandgap of the photovoltaic cells $[4,5]$. The second approach involves the combination of a non-selective or broadband emitter (e.g. gray body) and an optical filter that passes only a selected part of the spectrum. To obtain high conversion efficiencies, these filters should have high reflectance for the out-of-band radiation and thus "recycle" unusable radiation to the emitter.

The combustion system for a fuel-fired TPV system must be configured to provide heat fiux to the emitter uniformiy, at the design rate. Selective emitter systems have been configured with porous emitters with gaseous fuels burning on the emitter surface [6]. With non-porous emitters, the flow of products of combustion on the inside of the emitter surface must be controlled to achieve the desired flux profile.

Fuel fired TPV systems can be configured as cogeneration systems or electric power only systems. To achieve the highest efficiency for electric power production the waste heat must be recovered in combustion air preheat. Efficiencies (fuel to electric) which have been achieved to date in fuel fired TPV systems are less than 10\%, although efficiencies of $20 \%$ or higher have been projected.

The TPV system being developed here generates 500 watts of electric power from diesel fuel for portable applications. A low-pressure air-atomizing nozzle sprays fuel into a combustor. The hot gases exiting the emitter transfer most of their remaining heat to the incoming air through a compact recuperator. The infrared emission is converted to electricity using a proprietary filter/GaSb photovoltaic cell converter developed by Edtek, Inc. [7]. A simple overall system illustration is provided in Figure 5. Here the burner, emitter, and recuperator systems are contained inside of a double wall quartz vacuum chamber to control convective heat loss. The optical filters are inside of the vacuum chamber, mounted on the inner surface of the outer quartz cylinder. The cells are mounted on the outside of this same quartz cylinder.

The burner developed for this application is an adaptation of the low pressure air atomizing system. The internal nozzle components were resized for operation at the design steady state input rate of $3 \mathrm{~kW}$ and the design air preheat of $1200{ }^{\circ} \mathrm{C}$. The system has been developed with $100 \%$ of the combustion air flow through the atomizing nozzle. In view of high flame temperatures and high temperature of the atomizing air, it was necessary to incorporate novel features into the design to prevent the possibility of fuel coking. These features include fuel injection towards the tip of the pre-filming surface to minimize the residence time on the hot surface and cooling of the fuel line. The fuel line is cooled by circulating excess fuel almost to the injector tip. This cooling fuel is from 
the fuel system pressure regulator bypass and circulates in an outer jacket in the fuel line assembly. Air enters the nozzle radially rather than axially as in the systems described above and radial-flow swirl vanes were developed for this application. The swirler and the body of the atomizer are made of Inconel ${ }^{\text {(3) }}$ alloy to withstand the high temperature environment. Parts that would come in contact with the hot combustion gases are made mostly of ceramic materials. The burner is ignited by a pilot flame at starting which, in turn, is lit by a hot surface type igniter, modified to accommodate the piloting flow of fuel. The hot surface / pilot flame approach is selected over a spark system primarily due to weight considerations. The flame is 'proved' by a thermocouple, whose output is integrated into the control system.

During startup of the TPV burner system the combustion air is obviously much colder than in steady state. At the steady state design air flow rate this would produce a very low pressure

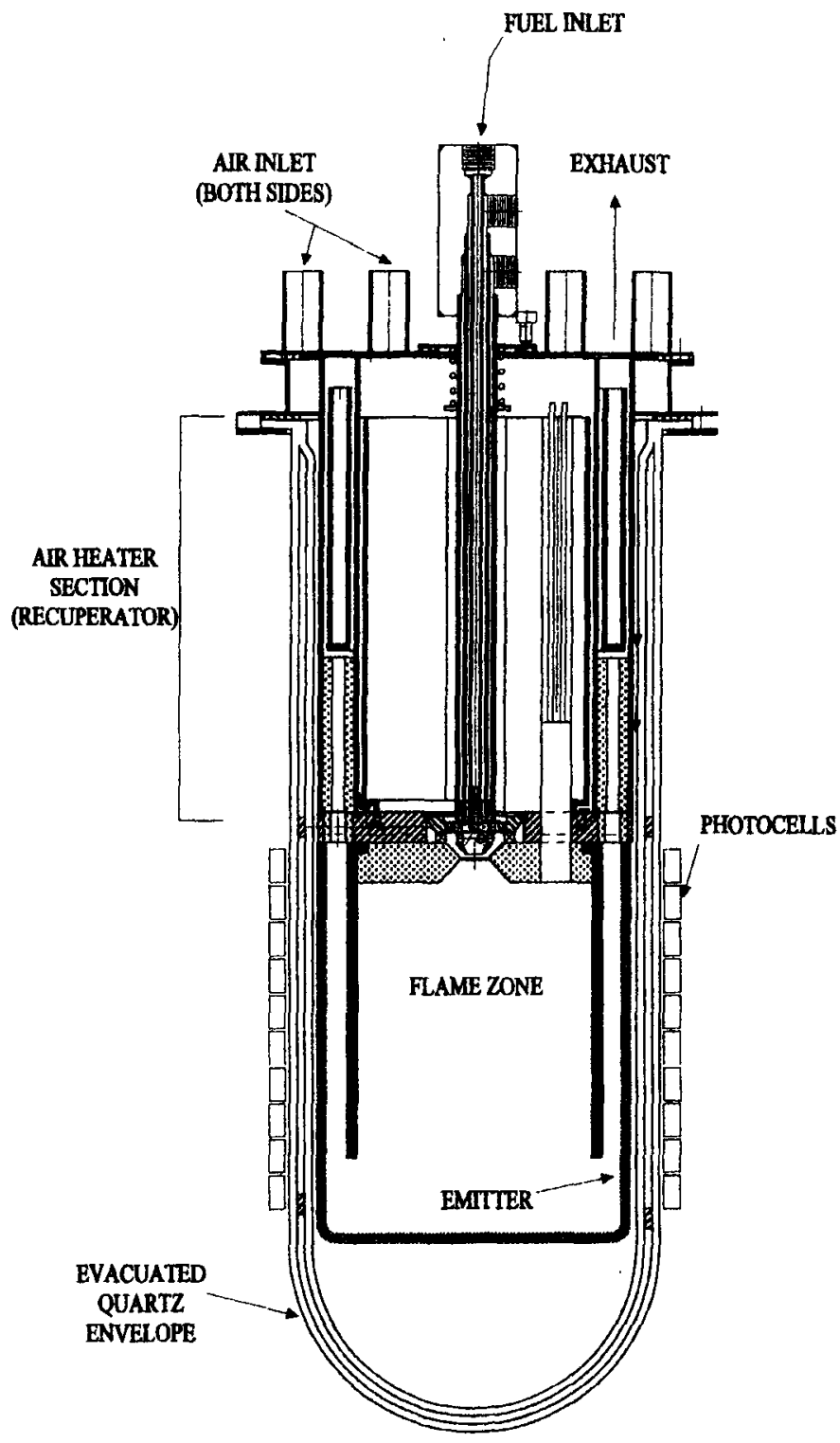

Figure 5. Oil-fired TPV system drop and low air velocity across

the atomizing nozzle and the atomization quality would be extremely poor. In consideration of this the air flow and firing rate are increased at start up to the $8 \mathrm{~kW}$ level. This is reduced to the steady state level about 2 minutes after startup.

\section{Performance}

Performance testing of the two domestic heating burners described above has been done in a wide variety of applications of interest to the U.S. industry including warm air furnaces, cast iron sectional boilers, and steel boilers. Considerable detail can be found in References 1 and 2. Performance of both burners is similar, with somewhat better results in most applications for the burner developed with higher atomizer air flow. The 
burners operate smoke free to excess air levels under $10 \%$. $\mathrm{NO}_{\mathrm{X}}$ levels are very much appliance dependent but are typically in the $60-70 \mathrm{ppm}$ range. As discussed above, achieving lower $\mathrm{NO}_{\mathrm{X}}$ levels is really constrained by the selection of the operating control.

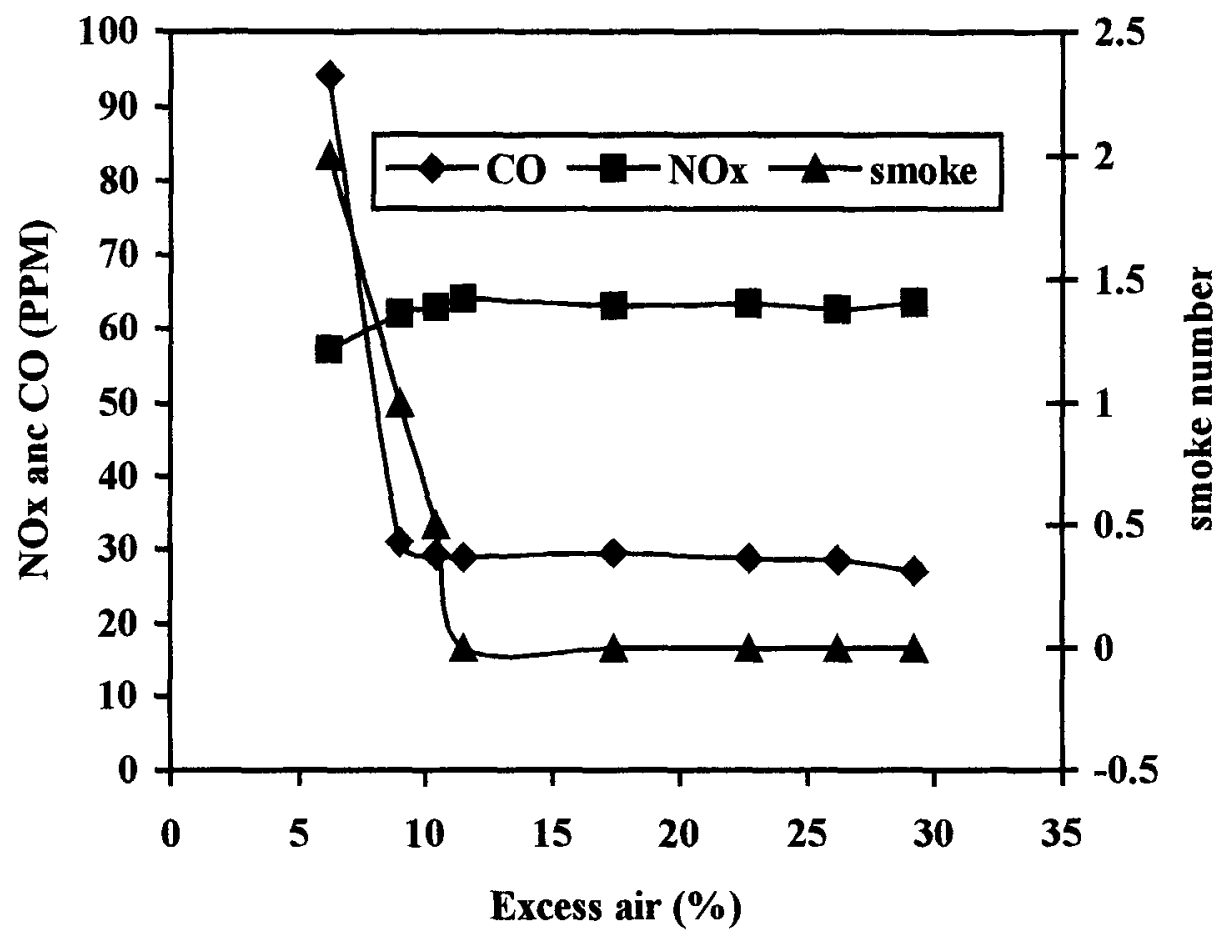

Figure 6. Typical performance data for burner head shown in Figure 4 in a steel boiler with a horizontal, cylindrical combustion chamber.

Figure 6 shows typical steady state performance test results for the second domestic burner configuration in a steel boiler with a horizontal, cylindrical combustion chamber. Excess air in this case was adjusted for these tests by modifying atomizing air pressure.

Much less performance data is currently available with the oil-fired TPV system simply because of the system current state of development. In steady state, at conditions close to design, the system operates with low CO (under $50 \mathrm{ppm}$ ) and smoke emissions at $20 \%$ excess air. $\mathrm{NO}_{\mathrm{X}}$ emission levels are quite high, due to the air preheat level, at $300 \mathrm{ppm}$.

\section{Discussion}

Overall, the low pressure, air atomization approach appears to offer a serious alternative to pressure atomization for the combustion of liquid fuels, particularly for low firing rates. The air pressures required and air velocities are certainly higher than is customary for pressure atomized burners and this presents some challenges as well as some opportunities. Achieving the higher pressures requires greater investment in the burner's fan. Newer brushless DC motor/fan sets can be used and offer very low electric power consumption. There is certainly a fan noise /size tradeoff which must be considered. In development work at BNL fans with diameters ranging from 90 to $180 \mathrm{~mm}$ have been 
evaluated. The smallest fans operate at very high speed $(18,000 \mathrm{rpm})$ and noise is a concern. The noise produced by the configuration described in Sections 3-5 above has been measured and is comparable or lower than for pressure atomized burners. The selection of the fan, fan cost, and integration of the fuel pump are seen by the authors as the major development issues with this approach.

The high fan pressures can lead to small air passage sizes in the burner head. Care must be given in burner development to avoid the need for critical tolerances in parts which may be stamped. The higher air velocity produced in this burner can lead to flame instability and the flame tube, as well as design of air distribution around the head, are important factors in controlling this. The higher velocities, however, provide opportunity for high internal gas recirculation rates. In development tests $\mathrm{NO}_{\mathrm{x}}$ levels as low as 32 ppm were achieved with blue flames.

\section{References}

1. Butcher, T.A. Advanced oil burner for residential heating - development report. Brookhaven National Laboratory Report BNL 62077, July 1995.

2. Butcher, T.A. Development of a low pressure, air atomized oil burner with high atomizer air flow, Brookhaven National Laboratory Report BNL 66160, January 1998.

3. Lefebvre, A.H. Gas Turbine Combustion, pp. 413-448. Hemisphere Publishing Corporation (1983).

4. Schubnell, M. Paul Gabler, H. Broman, L. Overview of European activities in thermophotovoltaics, Third NREL Conference on Thermophotovoltaic Generation of Electricity, AIP Conference proceedings 401, American Institute of Physics, Woodbury, New York, 1997.

5. Couts, T. and Fitzgerald, M. Thermophotovoltaics, Scientific American, September 1998.

6. Krist, K. GRI Research on thermophotovoltaics, First NREL Conference on Thermophotovoltaic Generation of Electricity, AIP Conference Proceedings 321, American Institute of Physics, Woodbury, New York, 1997.

7. Horne, W.E., Morgan, M.D., and Sundaram, V.S., IR filters for TPV converter modules, Second NREL Conference on Thermophotovoltaic Generation of Electricity, AIP Conference proceedings 358, American Institute of Physics, Woodbury, New York, 1995.

Acknowledgements - Sponsors of the work described here include the United States Department of Energy, the New York State Energy Research and Development Authority, and the United States Army. 